\title{
AVALIAÇÃO DO USO DE RESÍDUOS DA AGROINDÚSTRIA DE ÓLEOS VEGETAIS COMO FONTE DE CARBONO PARA A PRODUÇÃO DE CELULASES POR Aspergillus tubingensis AN1257 EM FERMENTAÇÃO EM ESTADO SÓLIDO
}

\author{
J. L. PIMENTA ${ }^{1}$, A. P. COURA ${ }^{2}$, R. S. SANTOS ${ }^{3,4}$, A. P. F. C. VANZELA ${ }^{3,4}$, L. A. PANTOJA ${ }^{1,3}$, \\ A. S. SANTOS ${ }^{2,3}$ \\ ${ }^{1}$ Instituto de Ciências e Tecnologia - UFVJM \\ ${ }^{2}$ Departamento de Ciências Básicas - UFVJM \\ ${ }^{3}$ Programa de Pós-graduação em Biocombustíveis - UFVJM, \\ ${ }^{4}$ Departamento de Farmácia - Universidade Federal dos Vales do Jequitinhonha e Mucuri - UFVJM \\ e-mail para contato: jejelopes92@hotmail.com
}

\begin{abstract}
RESUMO - O desenvolvimento de tecnologias que permitam a produção das enzimas a um custo competitivo é de grande importância não só para a área de biocombustíveis, mas para diversas aplicações biotecnológicas. Este estudo teve como objetivo avaliar diferentes resíduos de oleaginosas como fonte de carbono para a produção de enzimas celulolíticas por Aspergillus tubingensis AN1257. As tortas de algodão, macaúba, mamona, dendê, girassol, pinhão-manso foram avaliadas quanto ao potencial de indução para a produção de enzimas com atividade FPásica durante 14 dias de fermentação em estado sólido. Foi utilizado como inóculo uma suspenção de $1 \times 10^{7}$ conídios/g de torta. Todas as tortas induziram a produção de celulase, destacando-se as tortas de pinhãomanso (atividade FPase de 1,73 U/g de torta o que equivale a um extrato com $0,26 \mathrm{U} / \mathrm{mL}$ ) e algodão (atividade FPase de 1,86 U/g de torta, equivalente a 0,28 U/mL), ambas após 7 dias de fermentação em estado sólido.
\end{abstract}

\section{INTRODUÇÃO}

A necessidade do desenvolvimento de tecnologias que solucionem o problema do acúmulo e descarte de resíduos agroindustriais na natureza tem refletido em estudos e pesquisas voltados ao aproveitamento destas biomassas de modo a causar menos impactos ao meio ambiente. Neste cenário, cabe destacar os resíduos oriundos do processamento de oleaginosas para a produção do biodiesel (tortas ou farelos) os quais geralmente não passam por processo de agregação de valor porque são desconhecidas as suas potencialidades nutricionais e econômicas, salvo algumas exceções como soja, algodão e girassol (Abdalla et al., 2008).

As biomassas supracitadas apresentam em sua constituição três grupos principais de polímeros, a lignina, celulose e hemicelulose. Devido à presença dos carboidratos, uma estratégia possível para 


\section{9 a 22 de outubro de 2014 \\ Florianópolis/SC}

promover uma maior agregação de valores a estes resíduos seria a sua utilização como fontes de carbono em processos fermentativos por micro-organismos para produção de enzimas celulolíticas. Estas enzimas são compostas por um complexo de biocatalizadores altamente específicos que atuam em sinergia para a liberação de açúcares a partir da hidrolise de materiais celulósicos. Este tipo de processo hidrolítico vem sendo amplamente estudado pelo setor energético devido à possibilidade de sua aplicação em biomassas agroindustriais para produção de etanol (Castro et al., 2010).

Neste panorama, a alguns resíduos das indústrias de biodiesel têm sido relatados como fontes de carbono para produção de enzimas celulolíticas, como torta de dendê (Alam et al., 2005), resíduos de amendoim (Vyas e Vyas, 2005), torta de pinhão-manso (Ncube et al., 2012), torta de mamona (Herculano et al., 2011). A utilização de resíduos da cadeia do biodiesel em bioprocessos para obtenção de enzimas tem se mostrado como ferramenta economicamente promissora, pois além de agregar valores aos coprodutos, permitirá a redução do custo do processo de produção de enzimas hidrolíticas.

Neste contexto, o presente trabalho teve por objetivo avaliar o potencial indutor das tortas de algodão, dendê, girassol, macaúba, mamona e pinhão-manso quando utilizadas como fontes de carbono em processo de fermentação em estado sólido (FES) para produção de celulases por Aspergillus tubingensis AN1257.

\section{METODOLOGIA}

\subsection{Obtenção e preparo das tortas}

A torta de algodão utilizada neste estudo foi doada pela Indústria de Óleo, Rações e Plásticos Montes Claros LTDA - localizada no município de Montes Claros, MG; a torta de girassol foi doada pela empresa BIOSEP, localizada no município de Três Pontas, MG; a torta de macaúba foi doada pela Unidade de Beneficiamento do Coco de Macaúba - UBCM, localizada na cidade de Mirabela MG; as tortas de mamona e pinhão manso foram obtidas a partir do processamento de sementes doadas pela empresa de pesquisa agropecuária de Minas Gerais - EPAMIG, fazenda experimental de Nova Porteirinha, MG; a torta de dendê foi doada pela indústria e refinaria AGROPALMA, PA.

\subsection{Obtenção e manutenção das linhagens de fungos}

A linhagem do fungo filamentoso utilizada neste estudo, Aspergillus tubingensis AN1257, foi selecionada a partir de resultados de triagem realizada anteriormente. $\mathrm{O}$ micro-organismo foi mantido no Laboratório de Bioprocessos e Biotransformação - UFVJM, estocado em tubos de ensaio contendo meio PDA (potato dextrose ágar) e conservado sob refrigeração $\left(4 \pm 1^{\circ} \mathrm{C}\right)$.

\subsection{Processo fermentativo para produção de celulase}

O crescimento da linhagem Aspergillus tubingensis AN1257 para obtenção do inóculo foi realizada por repicagem da cultura estoque em placas de Petri com meio sólido PDA, as quais foram incubadas a $30^{\circ} \mathrm{C}$ por 7 dias. A solução de conídios foi obtida assepticamente por adição de $5 \mathrm{~mL}$ de 


\section{9 a 22 de outubro de 2014 \\ Florianópolis/SC}

meio líquido segundo Mandels e Sternberg (1976) em cada placa de cultura, seguida de raspagem com alça de drigalski. Posteriormente as soluções de conídios foram coletadas com auxílio de pipeta de Pasteur e filtradas através de gaze estéril. A concentração de conídios da solução obtida foi determinada por contagem em Câmara de Neubauer. O inóculo foi preparado a partir da solução filtrada de conídios devidamente diluída em meio líquido (Mandels e Sternberg, 1976) de forma a se obter uma concentração final de 1,43 x $10^{7}$ conídios/ml.

A linhagem Aspergillus tubingensis foi avaliada quanto ao desempenho na produção de celulases em processos de fermentação em estado sólido (FES), em meios elaborados com tortas de algodão, dendê, girassol, macaúba, mamona e pinhão-manso como fontes de carbono. Os ensaios foram realizados em frascos Erlenmeyer de $50 \mathrm{~mL}$ contendo 3 gramas de torta seca acrescidos de 2,1 $\mathrm{ml}$ de inóculo (70\% de umidade). Deste modo a concentração final do inóculo foi de $1,0 \mathrm{x}$ $10^{7}$ conidios/grama de torta. $\mathrm{O}$ processo fermentativo foi conduzido por 14 dias, a $30^{\circ} \mathrm{C}$ em estufa incubadora sem agitação, onde a cada 48 horas foi realizada a determinação da atividade xilanolítica.

A obtenção dos extratos enzimáticos foi realizada por adição de $20 \mathrm{ml}$ de tampão citrato, $\mathrm{pH}$, $100 \mathrm{mM}$, gelado, em cada ensaio seguido de agitação vigorosa em vórtex. Posteriormente os extratos foram filtrados em funil de Büchner a vácuo utilizando papel de filtro e recolhidos em tubos de ensaio imersos em gelo em escama contido dentro de Kitassato. Os filtrados foram mantidos em gelo até a quantificação das enzimas com atividade FPásicas.

A atividade FPásica foi determinada por quantificação de açúcares redutores (Miller, 1959) liberados após 60 minutos em um meio reacional, à $50{ }^{\circ} \mathrm{C}$, contendo aproximadamente $50 \mathrm{mg}$ de papel de filtro e 1,5 ml de extrato enzimático devidamente diluído em tampão pH 5 (Ghose, 1987). A atividade de FPase foi expressa em U/g de torta, onde uma unidade (U) foi definida como sendo a quantidade de enzima capaz de liberar $1 \mu \mathrm{mol}$ de açúcares redutores, por minuto de reação.

\section{RESULTADOS E DISCUSSÕES}

\subsection{Processo fermentativo para produção de enzimas lignocelulolíticas}

O gráfico representado pela Figura 1 ilustra as atividades máximas de Fpase (U/g de torta) dos extratos brutos produzidos pela linhagens AN1257 (Aspergillus tubingensis), por processo de fermentação em estado sólido (FSb), em meios elaborados com as tortas de algodão, dendê, girassol, macaúba, mamona e pinhão-manso. Observa-se que todas as tortas induziram a produção de celulase, porém as que melhor induziram a produção de enzimas com atividade FPásicas foram as tortas de algodão, com atividade FPase de 1,73 U/g de torta o que equivale a um extrato com 0,26U/mL e pinhão-manso, com atividade FPase de 1,86 U/g de torta, equivalente a 0,28 U/mL), ambas após 7 dias de fermentação em estado sólido. Vale destacar que estes resultados foram próximos aos relatados por Santos et al. (2011), em estudo utilizando uma linhagem de fungo do gênero Aspergillus em processo de fermentação em estado sólido. 


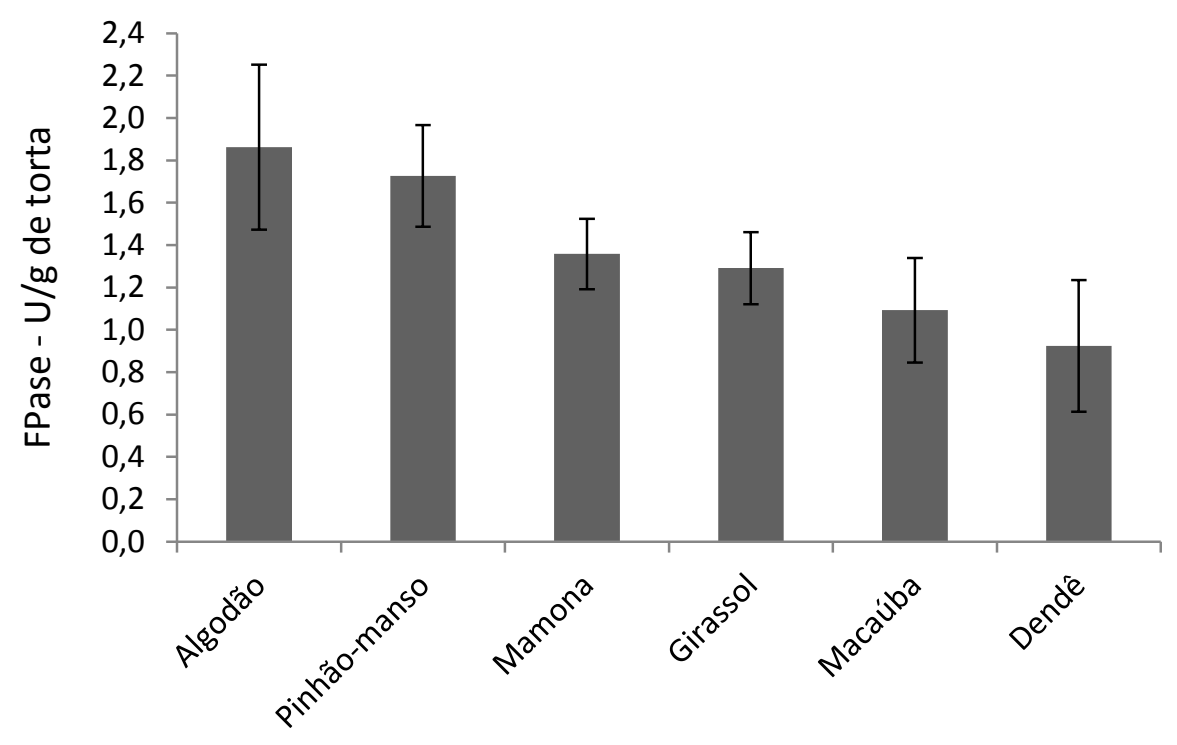

Figura 1 - Valores de produção máxima de enzimas com atividade FPásicas pela linhagem $A$. tubingensis AN1257, em processo de fermentação em estado sólido com uso de resíduos da cadeia produtiva de biodiesel como fonte de carbono

O gráfico representado na Figura 2 demonstra o perfil fermentativo para produção de enzimas com atividade FPásicas por A. tubingensis AN1257 em processos de fermentação em estado sólido utilizando as torta de algodão e pinhão-manso como fonte de carbono.

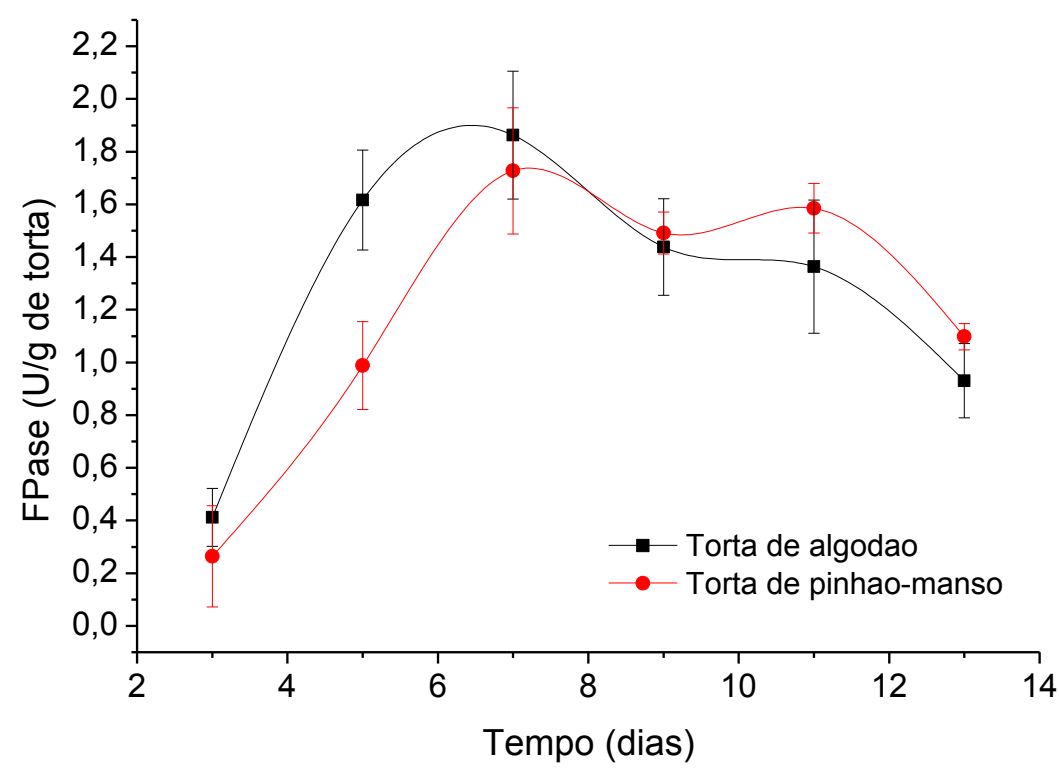

Figura 2 - Perfil de produção de enzimas com atividade FPásica por A. tubingensis AN1257 em fermentação em estado sólido utilizando tortas de algodão e pinhão-manso como fonte de carbono. 


\section{9 a 22 de outubro de 2014 \\ Florianópolis/SC}

Os resultados obtidos mostraram-se promissores induzindo a sequência de uma próxima etapa de estudos que será investigar a produção de outras enzimas lignocelulolíticas (endoglucanase, exoglucanase e $\beta$-glucosidase) e compreender as relações entre as variáveis relacionadas ao processo fermentativo (umidade, concentração e tipos de fontes de nitrogênio, concentração de conídios, temperatura, $\mathrm{pH}$, aeração) por meio de processos de otimização.

\section{CONCLUSÕES}

Apesar de celulases serem comumente comercializadas, vale ressaltar que a produção brasileira destas enzimas não atende a demanda nacional, havendo necessidade de importação das mesmas. Diante do exposto, há necessidade de estudos voltados para a produção de enzimas lignocelulolíticas a fim de torná-las mais acessíveis e com baixo custo. Sendo assim, este trabalho contribuiu de forma positiva na obtenção de dados científicos relevantes para a modificação deste cenário. Deve-se salientar que utilização de resíduos provenientes da extração lipídica de oleaginosas, oriundos da cadeia de produção do biodiesel, como fonte de carbono em processos de fermentação por fungos filamentosos se mostrou relevante para produção de celulases, por agregar valor a coprodutos subutilizados, bem como pela sua eficiência quando utilizados como substratos em processos fermentativos.

\section{REFERÊNCIAS}

ABDAllA, A. L.; SILVA FILHO, J.C.; GODOI, A.R.; CARMO, C.A.; EDUARDO, J.L.P.. Utilização de subprodutos da indústria de biodiesel na alimentação de ruminantes. R. Bras. Zootec. [online], v.37, p. 260-268, 2008.

ALAM, M. Z.; MUHAMMAD, N.; MAHAMAT, M. E.; Production of cellulase from oil palm biomass as substrate by solid state bioconversion. Am. J. Appl. Sci. v. 2, p. 569-572, 2005 .

CASTRO A. M.; PEREIRA Jr. N. Produção, propriedades e aplicação de celulases na hidrólise de resíduos agroindustriais. Quimica Nova, v. 33, n. 1, p. 181-188, 2010.

GHOSE, T. K. Measurement of cellulose activities. Pure and Ap. Chem., v. 59, p. 257-268, 1987.

HERCULANO, P. N. et al. Cellulolytic Fungi from Castor CurrMicrobiol v. 62, p. 1416-1422, 2011.

MANDELS, M.; STERNBERG D. Recent advances in cellulase technology. J Ferment Technol v 54, p. 267-286, 1976.

MILLER, G. L. Use of dinitrosalicylic acid reagent for determination of reducing sugar. Anal.Chem., v.31, p. 426-428, 1959.

NCUBE T.; RACHMOND L. H.; ABOTSI E. K.; RENSBURG E. L. J.; NCUBE I. Jatropha curcas seed cake as substrate for production of xylanase and cellulase by Aspergillusniger FGSCA733 in solid-state fermentation. Ind. Crops and Prod. v. 37, p 118- 123, 2012.

SANTOS, T. C.; CAVALCANTI, I. S.; BONOMO, R. C. F.; SANTANA, N. B.; FRANCO, M. Optimization of productions of cellulolytic enzymes by Aspergillus niger using residue of mango a substrate. Ciência Rural, v.41, n.12, p. 2210-2216, 2011.

VYAS, A.; VYAS, D. Production of fungal cellulases by solid state bioprocessing of groundnut shell wastes. J. Sci. Ind. Res. v. 64, p. 767-770, 2005. 